\title{
Dietary Habits and Intakes Associated with Obesity and Overweight among Adolescents in the State of Qatar
}

Ghazi Daradkeh ${ }^{*}$, Asma Al Muhannadi', Chandra P $^{2}$, Adam Fadlalla $^{3}$, Moudi Al Hajr ${ }^{1}$ and H. Al Muhannadi ${ }^{1}$

${ }^{1}$ Department of Dietetics - AKH, Hamad Medical Corporation, Qatar

${ }^{2}$ Department of Medical Research, Hamad Medical Corporation, Qatar

${ }^{3}$ Qatar University, Qatar

\begin{abstract}
Background: In Arab countries particularly in Qatar, nutrition transition in food choices and dietary habits have been changed from healthy diet pattern to unhealthy fast food pattern. As a result overweight and obesity rates are increasing to alarming figures. The aim of this study is to assess the prevalence of obesity and overweight among adolescents in Qatar and its relation with their eating pattern.

Methods: A cross - sectional study of 1225 adolescents ( $51 \%$ male and $49 \%$ female), aged 15 to 18 years, were randomly selected from 21 secondary schools in Doha - the capital of Qatar during October 2012 and Feb 2013. Data was collected by using self - reporting questionnaire that included questions on their eating / drinking habits and anthropometric measurements, Statistical analysis were performed using the Statistical Package for Social Sciences software (SPSS, Version 15.0). The level of significance was set at $\mathrm{P}<0.05$.

Results: This study showed that the overall prevalence of overweight and obesity were $(18.5 \%$ and $19.1 \%)$ respectively. The prevalence of obesity among males $(25.3 \%)$ was significantly higher than among females $(12.6 \%)$ $p<0.0001$, while overweight prevalence of female $(21.0 \%)$ was significantly higher than among males $(16.3 \%)$. When the prevalence of obesity and overweight was combined together it was significantly higher among males $(25.6 \%)$ than in females (23.7\%). Waist circumference was significantly higher in males ( $77.82 \pm 17.3)$ than in females $(73.06$ \pm 10.2 ). Eating habits of the students showed that Frequency of foods intake (fruits, milk and energy drinks per week) was significantly higher among males than females, while intake of (sweets, French fries and cake/doughnuts) was higher among females than among males. Results shows there was no significance difference in frequency of other food items between males and females.
\end{abstract}

Conclusion: Overweight and obesity is prevalent, unhealthy food habits are common among adolescents. Nutrition and health educational programs are required to reduce the tendency of overweight and obesity and to improve their eating habits.

Keywords: Adolescents; Obesity; Overweight; Body mass index; Waist circumference; Waist height ratio; Food habits

\section{Introduction}

Nowadays childhood and adolescents obesity is a global concern because dramatic increase of its prevalence worldwide [1]. It is a risk factor for different chronic diseases including hyperlipidemia, hyper insulinemia, hypertension, and early atherosclerosis [2-4]. Moreover, it is associated with negative impact on mental, physical and social functions in children [5,6]. In Arab countries it has reached to alarming figures with prevalence rates ranging from $25 \%$ to $60 \%$ [7]. Energy imbalance (Excessive energy intake and physical inactivity) is the most significant cause for obesity and its related chronic diseases such as type 2 diabetes, metabolic syndrome, and high blood pressure [8]. Dramatically change of adolescence life style behavior and dietary habits in Middle East countries during past three decade as result of modernization [7] which characterized by excessive intake of energy, fat and salt became common habits. Al-Hazzaa showed that about one-third of Saudi adolescences consumed fast food more than 3 time a week [9] and about two-third consumed sugar-sweetened drinks more than 3 times/week. Musaigar found that one-third of Bahraini adolescent rarely ate fruits and/ or vegetable and about half of them do not eat breakfast daily [10].

\section{Methods}

The present study is school-based conducted between October 2012 and Feb 2013. The study protocol and procedures were approved by the ethics committee of Medical Research Center (MRC) of Hamad Medical Corporation and supreme of higher education-state of Qatar.
Male and female adolescence from grade 10, 11 and 12 of 21 secondary schools in Doha - the capital of Qatar were the study population. Multistage, stratified, random sampling technique was used for sample selection. In the first stage, schools were stratified into boys and girls school. The second stage, a systemic, random sampling technique was used to select the schools. The third stage schools were stratified into public and private schools. 14 public and 7 private schools were selected. The selection of public and private schools was proportional to population size. All students from the selected schools who were free from any physical and/or mental disabilities were eligible to participate in the study. All selected schools received a formal letter from the supreme of higher education to facilitate the study, as well; a formal consent was obtained from all students to be involved in the study. The final sample size consisted of 1225 students (625 males and 600 females, 968 students from public schools and 257 students from private schools).

*Corresponding author: Ghazi Daradkeh, Hamad Medical Corporation, ALkhor Hospital, Qatar, Tel: (+974) 4474 5281; E-mail: gdaradkeh@hmc.org.qa

Received July 10, 2015; Accepted July 17, 2015; Published July 22, 2015

Citation: Daradkeh G, Muhannadi AA, Chandra P, Fadlalla A, Hajr MA, et al (2015) Dietary Habits and Intakes Associated with Obesity and Overweight among Adolescents in the State of Qatar. J Nutr Disorders Ther S1: 005. doi:10.4172/2161. 0509.S1-005

Copyright: @ 2015 Daradkeh G, et al. This is an open-access article distributed under the terms of the Creative Commons Attribution License, which permits unrestricted use, distribution, and reproduction in any medium, provided the original author and source are credited. 
Citation: Daradkeh G, Muhannadi AA, Chandra P, Fadlalla A, Hajr MA, et al. (2015) Dietary Habits and Intakes Associated with Obesity and Overweight among Adolescents in the State of Qatar. J Nutr Disorders Ther S1: 005. doi:10.4172/2161- 0509.S1-005

Page 2 of 5

\section{Data Collection}

\section{Anthropometric measurements}

Body weight was measured in kilogram to the nearest $0.1 \mathrm{~kg}$ using a calibrated portable scale (seca 208, Vogal and Halke, Germany), with minimal clothing and without shoes. Height was measured in centimeters to the nearest $0.1 \mathrm{~cm}$ using a calibrated portable measuring rod, attached to the weighing scale, while the student in a full standing position (stood up straight, bare feet, with heels, buttock, and back touching the stadiometer). Body Mass Index (BMI) was calculated as the ratio of weight $(\mathrm{Kg})$ to height $\left(\mathrm{m}^{2}\right)$. BMI reference values were used to defined overweight and obesity in adolescent aged 14-17years, based on the classification of the International Obesity Task Force (IOTF) [11], while adults BMI cut off points for (overweight $25-29.9 \mathrm{~kg} / \mathrm{m}^{2}$ and obesity $\geq 30 \mathrm{~kg} / \mathrm{m}^{2}$ ) were used for participants aged 18 years. Waist Circumference (WC) was measured using plastic, non-stretchable measuring tape, at the level of the umbilicus to the nearest $0.1 \mathrm{~cm}$ while student standing and following normal expiration. Waist to height ratio (WHtR) was calculated as the ratio between $\mathrm{WC}(\mathrm{cm})$ and height $(\mathrm{cm})$.

\section{Assessment of dietary habits}

A validated, self-reported questionnaire was used for data collection $[12,13]$. The questionnaire was consisting of three parts. Part one: demographic information (age, sex, date of birth, class). Part two: anthropometric measurement: weight, height, BMI, WC and WHtR. Part three: food habits and intake which include healthy and unhealthy dietary habits and its related to how many times per week the participants consumed breakfast, fruits, vegetables (cooked and uncooked), milk and dairy products, sugar - sweetened beverages, sweets, cakes/doughnuts and chocolates, energy drinks and fast foods. The answers ranging from (never $=0$ intake) to (every day $=7$ time/week). Dietary habits were classified into three levels of intake: $<3$ times/week, $3-4$ times/week and $\geq 5$ times /week.

\section{Data analysis}

The data were analyzed using the Statistical Package for Social Sciences software (SPSS, Version 15.0). Questionnaires with missing data were excluded. Description statistics are presented as mean and standard deviation. Chi-squared test was used to find the significance between parameters (overweight, obesity, gender, and frequency of intake). The level of significance was set at $\mathrm{P}<0.05$.

\section{Results}

Demographic and anthropometric measurements of the students

\begin{tabular}{|c|c|c|c|}
\hline Demographic Variable & $\begin{array}{c}\text { Male }(n=625) \\
\text { Mean } \pm \text { SD }\end{array}$ & $\begin{array}{c}\text { Female }(n=600) \\
\text { Mean } \pm \text { SD }\end{array}$ & P-value \\
\hline Age(Years) & $16.32 \pm 0.98$ & $16.18 \pm 1.00$ & $<0.001$ \\
\hline Weight (kg) & $70.68 \pm 22.82$ & $58.35 \pm 13.40$ & $<0.0001$ \\
\hline Height (cm) & $166.31 \pm 7.75$ & $158.15 \pm 6.22$ & $<0.0001$ \\
\hline BMI $\left(\mathrm{Kg} / \mathrm{m}^{2}\right)$ & $25.63 \pm 8.29$ & $23.00 \pm 5.26$ & $<0.0001$ \\
\hline WC (cm) & $77.82 \pm 17.3$ & $73.06 \pm 10.22$ & $<0.0001$ \\
\hline WHtR & $0.46 \pm 0.09$ & $0.46 \pm 0.02$ & 0.432 \\
\hline Overweight (\%) & 16.3 & 21.0 & $<0.0001$ \\
\hline Obese (\%) & 25.3 & 12.6 & $<0.0001$ \\
\hline Overweight or obese (\%) & 25.6 & 23.7 & $<0.0001$ \\
\hline
\end{tabular}

Table 1: Demographic and anthropometric characteristics of the study sample. $\mathrm{SD}=$ Standard Deviation

Frequency of foods intake (fruits, milk and energy drinks per week) was significantly higher among males than females (Table 2). While intake of (sweets, French fries and cake/doughnuts) was higher among females than among males. Results shows there was no significance difference in frequency of breakfast, vegetables, Sugarsweetened drink, and fast foods intake per week between males and females.

are showed in (Table 1). Male adolescents were significantly $(\mathrm{P}<$ $0.001)$ younger $(16.32 \pm 0.98)$ years than females $(16.18 \pm 1.0)$ years. A significantly higher mean body weight $(\mathrm{P}<0.0001)$ and $\mathrm{BMI}(\mathrm{P}<$ $0.0001)$ was recorded in male students. The prevalence of obesity among males $(25.3 \%)$ was significantly higher than among females $(12.6 \%) \mathrm{p}<0.0001$, while overweight prevalence of female $(21.0 \%)$ was significantly higher than among males $(16.3 \%) \mathrm{p}<0.0001$. When the prevalence of obesity and overweight was combined together it was significantly higher among males (25.6\%) than in females (23.7\%). The overall prevalence of overweight and obesity were (18.5\% and $19.1 \%)$ respectively. Waist circumference was significantly higher in males $(77.82 \pm 17.3)$ than in females $(73.06 \pm 10.2)(\mathrm{P}<0.0001)$, while there was no significant difference in waist-height ratio between males and females (Tables 1-4).

\section{Discussion}

As a result of unhealthy food habits and intakes high prevalence of obesity among both genders was reported, it was significantly more prevalent among males (25.3\%) than among females (12.6\%). Similar results of the combined prevalence of overweight and obesity had been shown by AL- Hazzaa [14]. They reported that male adolescents were heavier and had significantly higher mean BMI value than females. Our findings also agreed with the results of other studies, conducted on Italian early adolescents, who reported the prevalence rates of overweight and obesity was higher among boys than girls [15] in Canadian [16], and in Cyprus adolescents [17]. Bin Zaal et al. [18] had

\begin{tabular}{|c|c|c|}
\hline Food Type & Male (n)Mean \pm SD times/week & Female(n)Mean \pm SD times/weeks \\
\hline Breakfast & $(628) 3.89 \pm 3.337$ & $(597) 3.88 \pm 2.302$ \\
\hline Vegetables & $(621) 5.16 \pm 2.538$ & $(594) 4.94 \pm 2.413$ \\
\hline Fruits & $(622) 4.85 \pm 2.229$ & $(593) 4.45 \pm 2.281$ \\
\hline Milk & $(622) 5.11 \pm 2.327$ & $(593) 4.69 \pm 2.422$ \\
\hline Sugar-sweetened drink & $(620) 5.02 \pm 2.626$ & $(594) 4.84 \pm 2.365$ \\
\hline Fast food & $(619) 3.9 \pm 2.441$ & $(593) 3.79 \pm 1.984$ \\
\hline French fries /chips & $(619) 3.42 \pm 1.846$ & $(594) 3.91 \pm 2.056$ \\
\hline Cake/doughnuts & $(618) 3.43 \pm 1.976$ & $(594) 3.77 \pm 2.096$ \\
\hline Sweets & $(620) 4.27 \pm 3.302$ & 0.196 \\
\hline Energy drinks & $(620) 2.42 \pm 2.081$ & $(594) 5.05 \pm 2.224$ \\
\hline
\end{tabular}

Table 2: Frequency of weekly consumption of selected food among adolescence. $\mathrm{SD}=$ Standard Deviation

The results of dietary habits among studied adolescents in Qatar relative to age, while controlling for the effect of sex, are shown in Table 3 . There were no significant differences between the ages in relation to weekly intakes of breakfast, vegetables, fruits, milk, sugar- sweetened drinks, fast food, French fries/chips, cake/doughnuts, sweets and energy drinks. 
Citation: Daradkeh G, Muhannadi AA, Chandra P, Fadlalla A, Hajr MA, et al. (2015) Dietary Habits and Intakes Associated with Obesity and Overweight among Adolescents in the State of Qatar. J Nutr Disorders Ther S1: 005. doi:10.4172/2161- 0509.S1-005

Page 3 of 5

\begin{tabular}{|c|c|c|c|c|c|}
\hline \multirow[b]{2}{*}{ Food type/age } & \multicolumn{4}{|c|}{ Age (yrs) } & \multirow[b]{2}{*}{ P-value } \\
\hline & $\underset{f}{15(y r) \text { Mean } \pm \text { SD }(n=288}$ & $\begin{array}{c}\text { 16(yr) Mean } \pm \text { SD } \\
(n=433)\end{array}$ & $\begin{array}{c}17(y r) \text { Mean } \pm \text { SD } \\
(n=330)\end{array}$ & $\begin{array}{c}\text { 18(yr) Mean } \pm \text { SD } \\
(n=173)\end{array}$ & \\
\hline Breakfast & $3.98 \pm 2.203$ & $3.86 \pm 2.270$ & $4.01 \pm 4.143$ & $3.58 \pm 2.226$ & 0.425 \\
\hline Vegetables & $5.06 \pm 2.34$ & $5.03 \pm 2.357$ & $5.08 \pm 2.832$ & $5.08 \pm 2.296$ & 0.994 \\
\hline Fruits & $4.92 \pm 2.302$ & $4.6 \pm 2.17$ & $4.64 \pm 2.272$ & $4.4 \pm 2.361$ & 0.114 \\
\hline Milk & $4.89 \pm 2.319$ & $4.85 \pm 2.412$ & $5.1 \pm 2.396$ & $4.77 \pm 2.38$ & 0.398 \\
\hline Sugar-sweetened drink & $4.84 \pm 2.215$ & $4.86 \pm 2.42$ & $5.21 \pm 2.826$ & $4.730 \pm 2.494$ & 0.117 \\
\hline Fast food & $3.67 \pm 1.905$ & $3.84 \pm 2.424$ & $4.07 \pm 2.305$ & $3.77 \pm 2.049$ & 0.153 \\
\hline French fries /chips & $3.7 \pm 1.926$ & $3.66 \pm 1.917$ & $3.76 \pm 2.06$ & $3.44 \pm 1.938$ & 0.352 \\
\hline Cake/doughnuts & $3.58 \pm 1.979$ & $3.52 \pm 1.972$ & $3.75 \pm 2.131$ & $3.55 \pm 2.125$ & 0.460 \\
\hline Sweets & $4.75 \pm 2.195$ & $4.77 \pm 3.728$ & $4.56 \pm 2.223$ & $4.42 \pm 2.294$ & 0.466 \\
\hline Energy drinks & $2.03 \pm 1.929$ & $2.07 \pm 1.89$ & $2.15 \pm 2.0277$ & $2.35 \pm 2.071$ & 0.334 \\
\hline
\end{tabular}

Table 3: Frequency of weekly consumption of selected food among adolescents based on age.

$\mathrm{SD}=$ Standard Deviation

The results of dietary habits among studied adolescents relative to sex, while controlling effect of age, are shown in Table 4. Males and females weekly consumption rates for most of foods assessed in the study (fruits, milk, French fries, cake/doughnuts, sweets and energy drinks) had significant difference $(P<0.05)$.

\begin{tabular}{|c|c|c|c|c|}
\hline \multirow{3}{*}{ Food type/age } & \multicolumn{3}{|c|}{ Frequency of Intake } & \multirow{3}{*}{ P-value } \\
\hline & $<3$ times/week & 3-4 times/ week & $\geq 5$ times/week & \\
\hline & $n(\%)$ & $n(\%)$ & $n(\%)$ & \\
\hline \multicolumn{5}{|l|}{ Breakfast } \\
\hline$M$ & $198(16.2)$ & $141(11.5)$ & $283(23.2)$ & \multirow{2}{*}{0.19} \\
\hline $\mathrm{F}$ & $214(17.5)$ & $157(12.9)$ & $230(22.2)$ & \\
\hline \multicolumn{5}{|l|}{ Vegetables } \\
\hline$M$ & $92(7.5)$ & $181(14.8)$ & $347(28.4)$ & \multirow{2}{*}{0.09} \\
\hline $\mathrm{F}$ & $122(10.0)$ & $168(13.9)$ & $310(25.4)$ & \\
\hline \multicolumn{5}{|l|}{ Fruits } \\
\hline$M$ & $102(8.4)$ & $201(16.5)$ & $318(26.0)$ & \multirow{2}{*}{0.04} \\
\hline $\mathrm{F}$ & $144(11.8)$ & $197(16.1)$ & $259(21.2)$ & \\
\hline \multicolumn{5}{|l|}{ Milk } \\
\hline$M$ & $94(7.7)$ & $178(14.6)$ & $347(28.4)$ & \multirow{2}{*}{0.02} \\
\hline $\mathrm{F}$ & $143(11.7)$ & $156(12.8)$ & $302(24.8)$ & \\
\hline \multicolumn{5}{|l|}{ sweetened drink } \\
\hline$M$ & $102(8.4)$ & $196(16.0)$ & $322(26.4)$ & \multirow{2}{*}{0.21} \\
\hline $\mathrm{F}$ & $114(9.3)$ & $199(16.3)$ & $288(23.6)$ & \\
\hline \multicolumn{5}{|l|}{ Fast food } \\
\hline $\mathrm{M}$ & $167(13.7)$ & $262(21.5)$ & $188(15.4)$ & \multirow{2}{*}{0.14} \\
\hline $\mathrm{F}$ & $193(15.8)$ & $234(19.3)$ & $173(14.3)$ & \\
\hline \multicolumn{5}{|l|}{ French fries } \\
\hline $\mathrm{M}$ & $210(17.2)$ & $279(22.9)$ & $129(10.6)$ & \multirow{2}{*}{0} \\
\hline $\mathrm{F}$ & $185(15.2)$ & $217(17.8)$ & $199(16.3)$ & \\
\hline \multicolumn{5}{|l|}{ Cake/doughnuts } \\
\hline$M$ & $220(18.1)$ & $258(21.2)$ & $138(11.3)$ & \multirow{2}{*}{0.015} \\
\hline $\mathrm{F}$ & $206(16.9)$ & $213(17.5)$ & $183(15.0)$ & \\
\hline \multicolumn{5}{|l|}{ Sweets } \\
\hline$M$ & $151(12.4)$ & $236(19.3)$ & $232(19.1)$ & \multirow{2}{*}{0} \\
\hline $\mathrm{F}$ & $84(6.9)$ & $198(16.2)$ & $319(26.1)$ & \\
\hline \multicolumn{5}{|l|}{ Energy drinks } \\
\hline$M$ & $423(34.7)$ & $108(8.9)$ & $88(7.2)$ & \multirow{2}{*}{0} \\
\hline $\mathrm{F}$ & $497(40.8)$ & $53(4.3)$ & $50(4.1)$ & \\
\hline
\end{tabular}

Table 4: Frequency of weekly consumption of selected food among adolescents based on sex.

reported same finding of overweight proportion (18.5\%) and obese males $(22.2 \%)$ was higher than that of overweight (13.1\%) and obese (20.5\%) females in Dubai, United Arab of Emirates [10,19].

The present study found the frequency of fruits, milk and energy drinks intakes were significantly higher among males than among females, similar results were reported by other studies [14,20-24].
This study showed that undesirable eating habits are common among adolescents, as have been shown by studies from other countries, for example, data from the 2009 National Youth Risk Behavior Surveillance conducted in the United States showed that about $78 \%$ of high school students had not eaten fruit and vegetables five or more times per day [21]. Findings from the 2004-2005 National Health Survey-Australia [22] showed that $30 \%$ of $12-14$ year olds 
Citation: Daradkeh G, Muhannadi AA, Chandra P, Fadlalla A, Hajr MA, et al. (2015) Dietary Habits and Intakes Associated with Obesity and Overweight among Adolescents in the State of Qatar. J Nutr Disorders Ther S1: 005. doi:10.4172/2161- 0509.S1-005

Page 4 of 5

usually ate four or more daily servings of vegetables or three or more daily servings of fruit.

A similar survey to the one used in the present research, which was conducted on Saudi adolescents showed that less than quarter of Saudi adolescents consumed vegetables and fruits daily [14].

Higher males frequency intakes of fruits, milk and energy drinks was reported by this study than in females, had been agreed with ALHazzaa et al. among Saudi adolescents [14]. Similar results was reported by Musager et al., who was found that males fruits consumption was double as of females intakes $\mathrm{p}<0.001$ [10], while French fries, sweets, cake and doughnuts intake was significantly higher among females than in males $\mathrm{P}<0.004$. A similar tendency for those items intakes has been reported among Bahraini adolescents by Musaiger et al. [19] and by Abu-Mweis et al. [20] among Jordanian adolescents. This study showed that sugar-sweetened drinks were consumed by around three fourth of adolescents for more than three times a week, $42.4 \%$ and $39.9 \%$ of Qatari males and females adolescents respectively. Similar finding $67.2 \%$ and $57.4 \%$ of Saudi adolescent males and females was reported by AL-Hazzaa [14]. In the United States, about $29.2 \%$ of high school students had drunk soda at least once per day [21]. The study showed that other food intakes: vegetables, sugar- sweetened drinks and fast foods were similar in both genders. Musaiger et al. [19] reported that there was no significant difference between gender and frequency of eating fast foods per week.

This study showed that skipping breakfast more than three times a week is a common habit among males (34.7\%) and females (35.1\%). Skipping breakfast was also observed among American and European children and adolescents, ranging from $10 \%$ to $30 \%$, depending on age-group, population and definition [23]. Skipping breakfast was also shown to be widespread in Arab adolescents. In Bahrain, significantly greater percentage of females (62.8\%) skipped breakfast compared to males (37.2\%) [10], in Saudi adolescents $71 \%$ and $80 \%$ among males and females, respectively [14], and about $10 \%$ of adolescent males and nearly $19 \%$ of females in the United Arab Emirates [18]. It is well recognized that omitting breakfast has negative impacts on cognitive performance, quality of overall diet, body weight, and emotional wellbeing.

\section{Limitations of the Study}

The data were self-reported and were dependent upon the students' recall by a valid and reliable questionnaire. The assessment of dietary habits was qualitative and based on frequency of intakes, no portion sizes were evaluated, no total energy intakes was measured. Furthermore, this study is a cross-sectional design and causality direction cannot be assumed. To obtain a good picture of energy balance status in this age group an assessment of total dietary intake and energy expenditure is necessary. Nevertheless, this study described the life style behaviors and provides valuable and significant information for the public health.

\section{Conclusion}

A higher prevalence of overweight and obesity was found among students in both genders. Skipping breakfast was common among adolescents, more frequent intakes of French fries and sweets were reported among female adolescents while fruit, milk, and energy drinks were more frequent in males. Promoting of health eating among Qatari adolescents is highly recommended. Environmental and socioeconomic factors associated with obesity and lifestyle among adolescents should be examined in future research.

\section{References}

1. World Health Organization (2000) Obesity: Preventing and managing the global epidemic. Report of WHO consultations. WHO Technical Report Series, Geneva 894.

2. Berenson GS, Srinivasan SR, Wattigney WA, Harsha DW (1993) Obesity and cardiovascular risk in children. Ann NY Acad Sci 699: 93-103.

3. Berenson GS, Srinivasan SR, Bao W, Newman WP, Tracy RE et al. (1998) Association between multiple cardiovascular risk factors and athero sclerosis in children and young adults. The New Engl J Med 338: 1650-1656.

4. Mahoney LT, Burns TL, Stanford W (1996) Coronary risk factors measured in childhood and young adult life are associated with coronary artery calci fication in young adults: the Muscatine study. J Am Coll Cardiol 27: 277-284.

5. Swallen KC, Reither EN, Haas SA, Meier AM (2005) Overweight, obesity, and health-related quality of life among adolescents: the National Longitudinal Study of Adolescent Health. Pediatrics 115: 340-347.

6. Reilly JJ, Wilson D (2006) ABC of obesity: Childhood Obesity. Br Med J 333 1207-1210.

7. Musaiger A, Takruri HR, Hassan AS, Abu-Tarboush H (2011) Food consumption patterns in Eastern Mediterranean Countries. Manama, Bahrain: Arab Center for Nutrition. 2012: 10.

8. Lobstein T, Baur L, Uauy R, IASO International Obesity Task Force (2004) Obesity in children and young people: a crisis in public health. Obes Rev 1: 4-104

9. Al-Hazzaa HM, Abahussain NA, Al-Sobayel HI, Qahwaji DM, Musaiger AO (2012) Lifestyle factors associated with overweight and obesity among Saudi adolescents. BMC Public Health 12: 354.

10. Musaiger AO, Bader Z, Al-Roomi K, D'Souza R (2011) Dietary and lifestyle habits amongst adolescents in Bahrain. Food Nutr Res 55.

11. Cole TJ, Bellizzi MC, Flegal KM, Dietz WH (2000) Establishing a standard definition for child overweight and obesity worldwide: international survey. BMJ 320:1240-1243.

12. Al-Hazzaa HM, Al-Sobayel HI, Musaiger AO (2011) Convergent validity of the Arab Teens Lifestyle Study (ATLS) physical activity questionnaire. Int J Environ Res Public Health 8: 3810-3820.

13. Al-Hazzaa HM, Musaiger AO, ATLS Research Group (2011) Arab Teens Lifestyle Study (ATLS): objectives, design, methodology and implications. Diabetes Metab Syndr Obes 4: 417-426.

14. Al-Hazzaa M, Nada A, Abuhussien, Hana Al- Sobayel, Qahwaji DM et al (2011) Physical Activity, Sedentary Behaviors and Dietary Habits among Saudi Adolescents Relative to age, Gender and Region. Int J Behav Nutr Phys Act 8: 140.

15. Vieno A, Santinello M, Martini MC (2005) Epidemiology of overweight and obesity among Italian early adolescents: relation with physical activity and sedentary behaviour. Epidemiologia e Psichiatria Sociale 14: 100-107.

16. Shields M, Tremblay MS (2010) Canadian childhood obesity estimates based on WHO, IOTF, and CDC cut-points. International Journal of Pediatric Obesity 5: 265-273.

17. Savva SC, Kourides $Y$, Tornaritis M, Epiphaniou-Savva M, Chadjigeorgiou SC et al. (2002) Obesity in children and adolescents in Cyprus. Prevalence and predisposing factors. International Journal of Obesity 26: 1036-1045.

18. Zaal AAB, Musaiger AO, D'Souza R (2009) Dietary habits associated with obesity among adolescents in Dubai,United Arab Emirates. Nutr Hosp 24: $437-$ 444

19. Hung HC, Joshipura KJ, Jiang R, Hu FB, Hunter D et al. (2004) Fruit and vegetable intake and risk of major chronic disease. Journal of Notational Cancer Institute 96: 1577-1584.

20. Abu-Mweisa SS, Tayyema RF, Bawadib HA, Musaigerc AO, Al-Hazzaad HM (2014) Eating habits, physical activity, and sedentary behaviors of Jordanian adolescents' residents of Amman Mediterranean Journal of Nutrition and Metabolism 7: 67-74.

21. Eaton DK, Kann L, Kinchen S, Shanklin S, Ross J et al. (2010) Youth risk behavior surveillance - United States, 2009. MMWR Surveill Summ 59: 1-142.

22. Australian Bureau of Statistics (2006) National Health Survey: Summary of Results, Australia 2004-05. Canberra: Australian Bureau of Statistics. 
Citation: Daradkeh G, Muhannadi AA, Chandra P, Fadlalla A, Hajr MA, et al. (2015) Dietary Habits and Intakes Associated with Obesity and Overweight among Adolescents in the State of Qatar. J Nutr Disorders Ther S1: 005. doi:10.4172/2161- 0509.S1-005

23. Rampersaud GC, Pereira MA, Girard BL, Adams J, Metzl JD (2005) Breakfast habits, nutritional status, body weight, and academic performance in children and adolescents. J Am Diet Assoc. 105: 743-760.
24. Tayyem RF, Al-Hazzaa HM, Abu-Mweis SS, Bawadi HA, Hammad SS et al. (2014) Dietary habits and physical activity levels in Jordanian adolescents attending private versus public schools EMHJ 20: 416-423. 